\title{
EL DEBER DE RENEGOCIAR EL CONTRATO DE BUENA FE EN ÉPOCAS DEL COVID-19
}

\author{
Gustavo Ordoqui Castilla \\ Universidad Católica del Uruguay, Montevideo, Uruguay \\ Recibido: 15/7/2020 - Aprobado: 22/7/2020 \\ doi: https://doi.org/10.26439/iusetpraxis2020.n50-51.5029
}

\begin{abstract}
RESUMEN. A raíz de la crisis mundial generada por la COVID-19, los contratos celebrados se ven perjudicados debido a que las circunstancias actuales han dado lugar a daños, tanto económicos como sociales, que dificultan el cumplimiento de lo pactado. El presente artículo busca enfatizar la importancia de la buena fe bajo una óptica tridimensional, para poder renegociar y conservar el contrato y sus obligaciones, tomando en cuenta la realidad social, las normas y los valores.
\end{abstract}

PALABRAS CLAVE: buena fe / renegociar / COVID-19 / conservación / obligaciones

\section{THE DUTY TO RENEGOTIATE THE CONTRACTS OF GOOD FAITH IN TIMES OF COVID-19}

ABSTRACT. As a result of the global crisis generated by COVID-19, contracts entered into have been affected by current events that have caused economic and social issues, which make it difficult to comply with the agreement. The present article seeks to emphasize the importance of good faith, under a tridimensional perspective, in order to renegotiate and keep contracts and their obligations, considering the social reality, the rules and the values.

KEYWORDS: good faith / renegotiate / COVID-19 / conservation / obligations 


\section{INTRODUCCIÓN}

El derecho se debe analizar como una realidad tridimensional, por lo que se ha de ponderar la realidad socioeconómica de los valores y las normas.

La trascendencia de este tema está determinada por la vivencia reciente que nos ha tocado enfrentar como consecuencia del análisis de una cantidad importante de casos en nuestro país en que, cuando se vieron en la necesidad de enfrentar las circunstancias que creaba el COVID-19 al limitar especialmente la libertad de circulación, cientos de acreedores - que no eran en principio los afectados - se dieron cuenta de que las prestaciones no eran posibles de cumplir y, con la idea de mantener el acuerdo vigente, renegociaron; asimismo, actuando de buena fe y con espíritu de justicia y colaboración, buscaron nuevas soluciones con la concesión de nuevos plazos, la revisión de la ecuación económica del contrato, entre otras medidas.

En un día tuvimos cuatro casos en los que los acreedores y la supuesta parte fuerte eran los que proponían la revisión actuando de buena fe. El tema de la renegociación del contrato se estudia generalmente de forma complementaria a lo que sucede con la aplicación de la teoría de la imprevisión.

Nosotros lo presentamos en la posibilidad de que las partes hayan pactado o que este surja fundado en el principio general y fundamental de la buena fe contractual (artículo 1291 y numeral 2 del Código Civil uruguayo), en atención a las circunstancias del caso en que se advierta que se han frustrado con claridad las posibilidades y el fin del contrato.

\section{ENFOQUE JURÍDICO TRIDIMENSIONAL APLICADO A LA COYUNTURA}

No podemos pensar que solamente con leer las normas vamos a saber el derecho. La situación que estamos viviendo ahora nos exige un conocimiento de la realidad tal cual es en su verdadera dimensión; nos exige acercarnos al ser humano; nos exige ponderar esas tres dimensiones que nos mencionaba Carlos Fernández Sessarego, porque es una necesidad fundamental. Como también nos decía el maestro, "hay que preparar al músculo para correr, hay que poner conocimiento para construir".

Si no nos ponemos de acuerdo en lo que vamos a buscar en el derecho, difícilmente nos vamos a poner de acuerdo en su solución; y más aún ahora que estamos viviendo un proceso sísmico en el que se mueven las estructuras básicas y tradicionales en las que se sustentaba la responsabilidad civil, porque se fundamenta la relación contractual.

Y es ante esta misma realidad tridimensional que surge el motivo por el cual vamos a tratar el tema propuesto, y hasta ya dimos el titular. Pero ello no fue algo que se me ocurrió a mí o que fui a buscar a los libros, sino que se trató de una vivencia que me tocó seguir como profesional de derecho en mi país. 


\section{Realidad socioeconómica}

La situación fue muy clara a partir del momento en que se dispuso la emergencia y se exhortó al país a quedarse en casa y tomar las medidas que pemitieran la mínima afectación de los derechos y daños lícitos que se pudieran establecer.

Ante el anuncio de las medidas adoptadas por el Gobierno, en dos o tres horas el teléfono de mi estudio sonaba y atendí a acreedores titulares - particularmente de los casos de arriendo- preocupados porque se les estaban yendo los deudores y los contratos estaban prácticamente sin sustento.

El arrendatario no podía desarrollar su función, y abandonaba la finca y la dejaba al propietario. En realidad, lo que estábamos acostumbrados a manejar eran conceptos en que el hecho fortuito llevaba a que se distorsionara el contrato. Empero, fue ante esta clase de situaciones que se empezó a visualizar una nueva forma de encarar la realidad contractual: el deber de renegociar.

Este es el deber básico y fundamental que nos enseña a ver una nueva dimensión del alcance de la buena fe, y que nosotros titulamos "El deber de renegociar el contrato de buena fe en épocas del COVID-19".

\section{¿Por qué?}

Porque, como concepto previo, dentro de esta concepción de aplicar el instituto de la buena fe a tales circunstancias, tenemos que poner en juego el otro elemento que nos falta de la visión tridimensional: los valores.

\section{Valores y derechos}

Primero, se ha de encarar la realidad que estamos asumiendo. Esta es grave, tremenda y se observan claramente las delimitaciones de los derechos sustanciales ante la necesidad de priorizar unos derechos sobre otros, como el de la salud sobre el de la circulación o la información en nuestro país.

Si bien ante esta realidad socioeconómica tenemos los valores, también es cierto que tenemos los derechos, que son la tercera dimensión; y de ese derecho hay que decir que es algo más - como nos enseñaba Fernández Sessarego- que el conocimiento de la norma. Es el conocimiento de la norma aplicada a esa realidad.

Es allí donde aparece un instrumento que es la ventana abierta por la que se oxigenan casi todos los sistemas jurídicos latinoamericanos y europeos: la consagración del principio de buena fe, que hasta ahora y por ahora lo tenemos en los efectos de los contratos, y está tratando de jugar una nueva categoría pasando los títulos preliminares como concepto fundamental del ejercicio de cualquier derecho, sea contractual o no. 
Este principio, en un determinado momento, trae dificultades para algunos por razones de inseguridad, y hemos tenido consideraciones académicas y enfrentamientos.

\section{LA BUENA FE NO ES UN INVENTO}

Se nos dice: “¡Cuidado con ese instrumento! ¡Hay que manejarlo con cuidado; nos trae inseguridad jurídica! ¡Es una fiera que hay que mantener dentro de la jaula!”.

Este instrumento de la buena fe no se reduce a ser tan solo un invento o una propuesta académica, sino que existe en las normas jurídicas. Son las propias normas del sistema las que abren la puerta para contemplar nuevas realidades y otorgarles flexibilidad a las reglas.

Si bien el principio de la autonomía de la voluntad es el límite básico que hay que respetar, no es sagrado ni absoluto, pues coexiste con el principio de buena fe, y esa buena fe es la que nos obliga a considerar valores no discrecionales o arbitrarios, es decir, aquellos fundados en la realidad de lo que está vigente en cada sistema jurídico.

Entonces, cuando empezamos a hablar del deber de renegociar, nos preguntamos: "¿Y en qué fundo el deber de renegociar? ¿Por dónde va ese deber de renegociar?".

Así, nuevamente aparecen las proyecciones que surgen del propio deber de actuar de buena fe, que son los deberes de la honestidad, la lealtad, la confianza, la cooperación, la solidaridad, entre otros. Estas no son simplemente bonitas palabras, sino que se trata de derechos esenciales con bases fundamentales en las disposiciones de los códigos civiles que regulan el principio de buena fe.

\section{PRINCIPIOS POSITIVIZADOS}

En nuestro país se está sosteniendo - y con mucha firmeza- que no se trata de principios meramente reconocidos en el Código Civil, sino que vienen como principios generales con el respaldo constitucional. Nuestra Constitución protege directamente todos los derechos inherentes a la persona $y$, aunque no se refiera específicamente al principio de buena fe, sí alude a los principios generales que son inherentes a toda persona.

Dentro de ellos, está el tratar como deber de colaborar con el otro y pretender que uno sea también tratado con la misma regla. El deber de buena fe atañe tanto al acreedor como al deudor. Entre ambos tienen que resolver las circunstancias a las que se enfrentan actualmente, con gran inestabilidad.

Llevamos ya en América varias naciones -el Perú es una de ellas- con obras escritas sobre la buena fe y nos hemos encargado de ver cómo va evolucionando este gran principio en distintos países. 
Hoy no tengo ninguna duda en decirles que la fuente del derecho contractual puede aparecer perfectamente identificada en la buena fe.

La buena fe contractual no es - repito- algo que se nos inventa, sino que se halla prevista por nuestros propios codificadores como ventana abierta a la nueva realidad. $Y$ esa ventana abierta es la que va a ver lo que está ocurriendo ahora y es la que nos va a decir: " $\mathrm{i} A$ ! Hay un deber de renegociar que se funda en la propia existencia de la buena fe, y en la aplicación que se tenga que dar del deber de renegociar también ha de estar ordenada la buena fe".

Es decir, no solamente en el fundamento de la obligación, sino que también tiene que darse a la hora de aplicarlo en la forma como se va a emplear este deber en ese principio fundamental de buena fe.

\section{NORMAS DE LOS CÓDIGOS CIVILES EN AMÉRICA Y DEL DERECHO TRANSNACIONAL QUE SE REFIEREN A LA BUENA FE COMO FUNDAMENTO NORMATIVO}

\section{Derecho trasnacional}

- Pautas de unificación utilizadas en la CEU.

- Principios Unidroit, artículos 2.1.15, 4.8, 5.1.2(c), 5.3.3 y 5.3.4.

- Principios Lando PECL, artículos 1:305, 2:301, 4:103, 4:107, 4:109, 4:410, 4:118, $5: 102,6: 102$ y $6: 111$.

- Código de los Contratos de la Academia lusprivatista.

- Convención de Viena.

- Principios, definiciones y reglas de un derecho civil europeo: el marco común de referencia (DCFR), artículos II.-1:106; II.-3:301; II.-7:201; II.-7:205; II.-7:207; II.-7:215; II.-8:102; II.-9:101; II.-9:403, 404, 405; III.-1:106; III.-1:110; III.-3:203, y VI.-5:401.

2. En el régimen general internacional

\section{Europa}

- Código Civil español, artículos 7.1 y 1258.

- Código Civil griego, artículo 288.

- Código Civil portugués, artículo 762, numeral 2.

- Código Civil BGB § 242 y el ZGB, artículo 2, numeral 1.

- Código Civil italiano de 1942, artículo 1124. 
- Código Civil francés, artículo 1135: "Las convenciones obligan no solo a aquello que se expresa, sino también a todas las cosas que la equidad, la costumbre o la ley otorgan a la obligación según su naturaleza".

\section{América}

- Código Civil chileno, artículo 1546:

Los contratos deben ejecutarse de buena fe, y por consiguiente obligan no solo a lo que en ellos se expresa, sino a todas las cosas que emanan precisamente de la naturaleza de la obligación, o que por la ley o la costumbre pertenecen a ella.

- Código Civil colombiano, artículo 1603:

Los contratos deben ejecutarse de buena fe, y por consiguiente obligan no solo a lo que en ellos se expresa, sino a todas las cosas que emanan precisamente de la naturaleza de la obligación, o que por la ley o la costumbre pertenecen a ella.

- Código Civil argentino (2014), artículo 9: "Principio de buena fe. Los derechos deben ser ejercidos de buena fe", y artículo 961:

Buena fe. Los contratos deben celebrarse, interpretarse y ejecutarse de buena fe. Obligan no solo a lo que está formalmente expresado, sino a todas las consecuencias que puedan considerarse comprendidas en ellos, con los alcances en que razonablemente se habría obligado un contratante cuidadoso y previsor.

- Código Civil brasileño, artículos 113, 187, 421 y 422.

- Código Civil ecuatoriano, artículo 1562.

- Código Civil paraguayo, artículos 714 y 715.

- Código Civil costarricense, artículo 1023.

- Código Civil portorriqueño, artículo 1210.

- Código Civil boliviano, artículos 725 y 726.

- Código Civil salvadoreño, artículo 1417.

- Código Civil hondureño, artículo 1546.

- Código Civil venezolano, artículo 1160.

- Código Civil panameño, artículo 1109.

- Código Civil cubano, artículo 6.

- Código Civil uruguayo, artículo 1291, numeral 2.

- Buena fe pasa a primera división: la refieren en el Título Preliminar, Texto Proyectos, Código Civil y Comercial argentino, artículo 9; Código Civil suizo, 
artículo 1, numeral 2; artículo 2, numeral 1, y artículo 3; Código Civil de Etiopía, artículo 375; Código Civil español, artículo 7, numeral 1, y proyecto peruano.

- Código Civil peruano (1984), artículo II: "Buena fe: los derechos se ejercen y los deberes se cumplen conforme a la buena fe".

- Código Civil peruano, artículo 1362: "Los contratos deben negociarse, celebrarse y ejecutarse según las reglas de la buena fe y común intención de las partes", y artículo 168: "El acto jurídico debe ser interpretado de acuerdo con lo que se haya expresado en él y según el principio de buena fe".

\section{Interpretación sistemática}

- Artículo 169: "Las cláusulas de los actos jurídicos se interpretan las unas por medio de las otras, atribuyéndose a las dudosas el sentido que resulte del conjunto de todas".

\section{Interpretación integral}

- Artículo 170: “Las expresiones que tengan varios sentidos deben entenderse en el más adecuado a la naturaleza y al objeto del acto".

\section{Interpretación contra el estipulante}

- Artículo 1401: “Las estipulaciones insertas en las cláusulas generales de contratación o en formularios redactados por una de las partes, se interpretan en caso de duda, a favor de la otra".

No hay ninguna duda de que estas normas conforman una columna vertebral del sistema jurídico mundial y que, hoy por hoy, no debe haber ningún país que puede inhibirse de ponderar estos valores a la hora de encargarse de resolver, por ejemplo, los principios contractuales del margen o al margen, o sobre esta buena fe que estamos manifestando.

En el Código Civil uruguayo contamos con el artículo 1291, numeral 2, que tiene sus similares en Colombia, Ecuador y la última legislación argentina, que señala: “Todos los contratos se tienen que ejecutar de buena fe y en consecuencia obligan no solo a lo que en ellos se expresa, sino a todas las consecuencias que sean conformes a su naturaleza, a la equidad y a la ley".

En la facultad, cuando transcribo o reproduzco este texto, casi siempre hago un minuto de silencio cuando llego al pasaje que indica: "Obligan no solo a lo que en ellos se expresa".

Sí, dije bien. Hay una cláusula de los códigos civiles de la mayoría de los países americanos -Uruguay es uno de ellos- que establece claramente que los contratos obligan a lo que en ellos se expresa y, entonces, ¿a qué nos obliga? En consecuencia, 
obligan no solo a todo lo que no dice, sino a todas las consecuencias según su naturaleza. ¿Cuál es la naturaleza? La causa, ya sea conforme a la equidad, el uso y la ley.

\section{SIN TEMOR A LA BUENA FE}

No le tengamos miedo a la buena fe. Seamos coherentes, defendamos la aplicación de estos principios. Yo no he encontrado todavía a nadie que me haya dicho: "Ordoqui, en mi país se aplicó abusivamente la buena fe".

Hay un grupo que tiene miedo de que se rompa el principio de la fuerza vinculante; sin embargo, no soy yo quien lo dice, sino que es la norma en sí la que lo manifiesta al referir: "Oblígame a lo que en ello se expresa, sino a todas las consecuencias que según su naturaleza sean conformes a la equidad o a la ley".

Este padrón de día aparece hoy ya no solamente en los códigos nacionales, internacionales y de normas transnacionales, sino también en códigos como el argentino del 2014, bien fresquito en su doctrina, que mantiene el mismo criterio. Y hoy quizá sea el momento de pensar con seriedad en la vigencia de estos principios de regulación con carácter latinoamericano y poder, de una buena vez por todas, decir que Latinoamérica tiene un derecho de los contratos como la Comunidad Europea posee el Unidroit, los principios Lando o el Código de los Contratos de la Academia lusprivatista de derechos privados.

Este es el momento, desgraciadamente, en que se nos mueve el piso y podemos replantear muchas cosas. Tenemos tiempo, probabilidades y varios medios de conexiones. Pensemos y repensemos, porque se nos va el futuro de nuestra materia en cómo organizamos este tipo de aspectos.

\section{BUENA FE PASIVA Y ACTIVA}

La buena fe tiene aspectos pasivos y activos. De ella se han derivado principios básicos, como el de la colaboración, el de la transparencia y el de la confianza - son como ramas de un árbol que se consolidan y se proyectan-; y hoy puedo decir claramente que de ese árbol de la buena fe sale una rama que es el deber de renegociar y de actuar con corrección, tratando de conservar el principio que tenemos en todos los contactos en las normas de interpretación del contrato; conservar el contrato que puede estar corriendo riesgo a la hora de tener que enfrentar todas las circunstancias que conocemos.

Decía yo que inclusive este deber de renegociar está apareciendo cada vez más en la instancia de la Comunidad Europea. Fíjense ustedes que nosotros podemos decirles que en la ley de modernización del Código Civil español en materia de obligaciones y contratos, artículo 1213.2; en el proyecto de la reforma de Pierre Catala, artículo 1125; 
Unidroit 6.2.3, y Lando 611, en todos está apareciendo insinuado el deber de renegociar aun en los casos en los que no se den estrictamente las hipótesis de casos fortuitos que se asemejan más, y aparece este instrumento cada vez más consolidado para no tener que entrar a discutir.

\section{EJECUCIÓN DEL CONTRATO}

Ahora, ¿hay imposibilidad absoluta con el tema del coronavirus al momento de ponderar la ejecución del contrato? ¿Es una imposibilidad temporal? ¿Es una imprevisión total? ¿Es una imprevisión parcial? ¿Cómo baso la imprevisión total si, por ejemplo, en nuestro país están definidas las leyes que regulan específicamente las situaciones de pandemia?

Antes de ingresar a la discusión de si hay caso fortuito se debe cumplir con el deber de renegociar bajo el fundamento de la buena fe. Hay tres o cuatro pautas que surgen de las aplicaciones generales acerca de cómo operaría ese deber de renegociar en la práctica; pero que nos quede claro que, como pilar fundamental, el deber lo estamos consolidando en la vigencia del principio de buena fe.

Se nos ha dicho que de la buena fe se deriva la obligación de seguridad en los casos de transportes y de accidentes hospitalarios, y siempre nos preguntamos de dónde surgió la obligación de seguridad.

La buena fe está fundada en el deber de colaboración y solidaridad. Hoy nadie duda de la existencia de la obligación de seguridad; tampoco deberíamos dudar de la exigencia del deber de renegociar en estas circunstancias fundadas precisamente en la buena fe. El contenido de este deber de renegociar, ¿cómo se plasma? Y aquí me estoy basando en las disposiciones mencionadas.

Pero de todas las disposiciones mencionadas - sobre todo de las últimas que se vienen generando- adviertan ustedes, a modo de ejemplo, que en la última legislación argentina del 2014, en el artículo 1011, aparece el derecho de rescisión en los contratos de suscripción continuada y, antes de rescindir un contrato, establece el deber de renegociarlo - tratar de evitar la rescisión o la extinción del contrato ya como figura independiente y complementaria-. Antes, pues, no teníamos el deber de renegociar en este tipo de situaciones jurídicas.

Ahora aparece por primera vez tomando forma en el mismo proceso. Para los que ya tenemos canas, esto se vivió cuando consolidamos la obligación de seguridad. Antes se decía: “¿Dónde está? Esto es un invento de los juristas en un momento de ilusiones. Es muy lindo tenerlas, pero ¿dónde está la norma que me hable de la seguridad, que me hable del deber de renegociar?". 
Se halla en la regulación del principio de buena fe y sus proyecciones, que son jurídicamente sustentables. No estoy hablando de sueños, sino de que esta postura y este alcance y proyección de la buena fe en la constitución de deberes como el de renegociar poseen sustento en la normativa que reconoció la buena fe, porque los sistemas jurídicos, cuando la reconocen, es porque saben sus proyecciones. Conocen que es una forma expresa de delegación de funciones en aquel que deberá decidir.

No podemos tener miedo de decir que se está creando un derecho sobre la base de las tensiones de los jueces cuando se sustentan en la buena fe. Y claro que es una máxima consolidada, como digo yo en la facultad, y tomo siempre como paralelo la obligación de seguridad frente al deber de renegociar, a raíz de que hubo una sentencia que lo dijo y otra que lo aceptó, y nadie lo duda. Sin embargo, no tenemos ninguna norma - por lo menos en nuestro derecho- que en forma expresa refiera que, si un paciente se cae de la cama, opera la obligación de seguridad; o que en el transporte, de la obligación de trasladar sana y salva a la persona, se traiga la obligación de seguridad. No hay ninguna norma que lo diga; empero, nadie duda de su vigencia.

Esa situación jurídica tenemos que ponderarla exactamente igual acá. Por ahora, en que estamos recién empezando un proceso en el cual el deber de renegociar consciente o inconscientemente ya está dándose en la práctica.

\section{LA RENEGOCIACIÓN}

Lo que me determinó a prenunciar esta temática fue una vivencia en la que, en un solo día, proyecté cuatro renegociaciones en estas épocas, en las que las partes se acercaron de buena fe. Las dos se dieron cuenta de que era una situación que las superaba.

No hay duda de que los contratos de arrendamiento son los que más complejidad nos generan en esta circunstancia, y ni al acreedor ni al deudor les servía terminarlo. Al acreedor, porque le iba a quedar el local vacío, y al deudor porque, cuando terminara la pandemia, iba a perder el negocio.

Entonces se sientan y razonan el problema de a dos; recomponen y revisan el alcance del contrato del principio como un acuerdo, lo que está perfectamente regulado en el sistema jurídico. Y de ahí uno ve la buena fe con la que se está procediendo. Cada uno colaborando para resolver el problema, que es el camino que nos parece más sensato a tener en cuenta. Pero, claro, el deber de renegociar es una obligación de medios y no apunta a asegurar un resultado.

Nadie puede decir que, porque se renegocia un contrato, seguramente en todos los casos se terminarán resolviendo los problemas. En algunos ocurrirá así y en otros no. La obligación de medios es aquello que implica actuar con la diligencia debida y esto sí es exigible, desde nuestro punto de vista; $y$, sobre la base de la vigencia de este principio, 
actuar con la diligencia debida para colaborar en la forma de poder conservar un contrato en esta situación de emergencia.

Más allá de la discusión acerca de si es un caso fortuito o uno de fuerza mayor, toda esa polémica que se genera en paralelo es extraordinaria; pero, antes de todo eso -y el segundo aspecto a considerar-, cuando las instituciones son reguladas, el deber de renegociar ha de ser planteado en un plazo razonable con cercanía al hecho. La renegociación no puede venir proyectada dos años después de que ocurrió un evento.

Entonces, la primera pauta respecto al contenido es que se trata de una obligación de medio. La segunda pauta es que debemos tener presente que ha de ser una verdad cercana o próxima, y después deben presentarse los requisitos propios para una renegociación en términos generales, que haya concretamente un hecho imprevisto, irresistible, extraordinario; figuras que se aparecen y que se acercan en nuestro derecho a una teoría de previsión.

\section{FALTA DE LA TEORÍA DE LA IMPREVISIÓN}

Nuestro país - junto con Chile y otros más- no posee un texto expreso sobre la teoría de la imprevisión. Sin embargo, cuando hemos tenido que afrontar situaciones complejas, hemos - sobre la base de la buena fe-sustentado el criterio de la teoría de la imprevisión no como un aspecto patológico, sino positivo, con los ánimos de reconstruir aquello que se pudo caer o romper, que es el equilibrio contractual. Es con ánimos positivos que actúan las partes y, por eso, se proyecta el deber de la buena fe en su faz activa, en suposiciones como el deber de colaboración para subsanar la situación que se ha de enfrentar - por cierto, sumamente compleja-.

La solicitud tiene que ser sin demora, y el plazo de duración tampoco ha de ser tan extensivo. Ahora viene la gran pregunta que se plantean los pocos estudiosos que desarrollan esta temática: ¿se debe aceptar una propuesta razonable? Si nosotros fuéramos jueces actualmente, ¿qué diríamos? Está claro que se encuentra vigente el principio de la autonomía de la voluntad y eso hay que respetarlo. Desde nuestro punto de vista no es que pueda quebrarse el principio de la autonomía de la voluntad con el principio de renegociación. Empero, lo que sí es exigible es que las partes - tanto deudor como acreedor-, por su proyección, demuestren que actuaron perfectamente dentro de la razón y la tolerancia para llegar a un accionamiento.

Si lo logran, excelente: habrá una revisión de contrato. Pero, si no lo consiguen -lo cual obviamente puede ocurrir-, esos elementos - siempre que supongan actuar de buena fe-van a ser de mucha utilidad para resolver en el futuro, cuando terminen encaminados hacia el quehacer jurídico a través de la decisión de un juez. Porque, si no hay acuerdo, obviamente es el juez quien va a decir si se procedió o no de buena fe. E incluso 
es allí donde se puede afirmar que tal persona no colaboró para nada con las circunstancias que había que encarar. Se aferró al principio de la autonomía de la voluntad y se quedó ciegamente enganchada. ¿Esa persona actuó correctamente? ¿Le podríamos reprochar que debió haber actuado con mayor buena fe en la revisión de la situación contractual?

Estos son los temas a los que tenemos que brindar respuestas y, de alguna forma, los estamos precisando con la existencia de este deber de renegociar.

\section{CONCLUSIONES}

Finalmente, debemos considerar al coronavirus no solo como una amenaza, sino también como una oportunidad para revisar la rutina de nuestras organizaciones. Las enseñanzas han de ser no solo éticas, sino jurídicas. Tenemos que aprender de estas circunstancias y de su resolución para presentar propuestas nuevas, más o menos precisas en relación con lo referido, y una de ellas la haremos como inminente a nivel mundial.

Nuestro pensamiento acerca de la regulación del deber de renegociar los contratos en situaciones extremas lo vemos reflejado - de alguna forma- en las palabras inteligente de José Luis Perales, cuando destaca que tenemos que darnos cuenta de que estamos viviendo un momento muy particular en el que la soberbia humana ha quedado arrodillada ante un microscópico enemigo. Como bien señala el cantautor, todo esto posiblemente nos sea apocalíptico, pero sí aleccionador. Quizá la humanidad necesitaba una sacudida que la despertara del letargo automático en el que vive, para que afloren valores naturales como la solidaridad y el bien común. Tal es la situación que vivimos en nuestro país.

En Uruguay se promulgó una ley mediante la cual se les descontó a todos los funcionarios públicos un $20 \%$ de su salario para distribuirlo entre los más pobres y así pudieran alimentarse durante la situación de crisis. Al saber de esta propuesta, creí que se generarían problemas. Sin embargo, la población de nuestro país en su totalidad la asumió como un deber de solidaridad y a todos se nos descontó ese 20 \% para distribuirlo a los más pobres.

Las agrupaciones que realizan las canastas solidarias - sin dinero del Estadohan logrado proyecciones realmente increíbles. Ello quiere decir que los valores que despiertan en este contexto son los que tenemos que asesorar y proyectar para que tengan cabida en los institutos jurídicos nuevos de cara al siglo XXI. La presencia de la buena fe ante las nuevas circunstancias y necesidades se revitaliza como un principio general básico en el fundamento y la aplicación del deber de renegociar. 
Lo cual estamos seguros de aplicar y que nos llevará por el buen camino; asimismo, posibilitará que, en definitiva, podamos seguir conviviendo entre amigos dentro de la pacificación y la reorganización social que tanta falta nos hace en estos momentos.

\section{BIBLIOGRAFÍA}

Bidart-Campos, G. (2004). Una mirada constitucional al principio de la buena fe. En M. Córdoba (Comp.), Tratado de la buena fe en el derecho (pp. 43-54). Buenos Aires: La Ley.

Carbonnier, J. (1963). Théorie des obligations. París: Thémis.

Cesàro, V. M. (2000). Clausola di rinegoziazione e conservazione dell'equilibrio contrattuale. Nápoles: Edizioni Scientifiche Italiane.

Chamie, J. (2008). Equilibrio contractual y cooperación entre las partes: el deber de revisión del contrato. Revista de Derecho Privado, (14), 113-138. Recuperado de https://revistas.uexternado.edu.co/index.php/derpri/article/view/552

Díez-Picazo, L., Rocca i Trías, E. y Morales y Ponce de León, A. (2002). Los principios del derecho europeo de los contratos. Madrid: Civitas.

Georgeoglou, K. (2 de abril del 2020). El impacto del coronavirus en el cumplimiento de los compromisos comerciales. Recuperado de https://home.kpmg/uy/es/home/ insights/2020/04/el-impacto-del-coronavirus-en-el-cumplimiento-de-loscompromisos.html

Marasco, G. (2006). La rinegoziazione del contratto. Strumenti legali e convenzionali a tutela dell'equilibrio negoziale. Padua: Casa Editrice Antonio Milani (Cedam).

Mosset Iturraspe, J., Falcón, E. M. y Piedecasas, M. A. (2002). La frustración del contrato y la pesificación. Buenos Aires: Rubinzal-Culzoni Editores.

Ordoqui, G. (1998). Lecciones de derecho de las obligaciones (t. III, vol. 2). Montevideo: Ediciones del Foro.

Ordoqui, G. (2008). Desequilibrio de los contratos. Montevideo: Universidad Católica del Uruguay.

Ordoqui, G. (2015). Tratado de derecho de los contratos (t. I). Montevideo: Ediciones Legales.

Ordoqui, G. (2017). Buena fe contractual. Montevideo: La Ley Uruguay.

Peirano, J. (1966). Curso de obligaciones. Montevideo: Centro de Estudiantes de Derecho.

Wieacker, F. (1977). El principio general de la buena fe. Madrid: Civitas. 